\title{
SOURCES OF CONFLICT IN PUBLIC HOSPITALS
}

\author{
E. Raykova", M. Semerjieva, D. Bakova \\ Department of Management of Health Care, Faculty of Public Health, Medical University-Plovdiv, \\ Bulgaria
}

\begin{abstract}
PURPOSE: The aim of this research is to identify the sources of conflicts at workplace in publichospitals in Bulgaria. METHODS: By means of direct individual poll was studied the opinion of 302 medical employees at four general hospitals. Of all respondents, $223(73.8 \pm 2.53 \%)$ were medical professionals and $79(26.2 \pm 2.53 \%)$ were physicians. We used a set of questions that determine sources of conflicts in hospitals. The data were analysed using descriptive statistics and non-parametric analysis at a significance level for the null hypothesis $\mathrm{p}<0.05$.The statistical analysis was performed using SPSS v. 16. RESULTS: Conflicts in hospitals are determined by the conditions and factors of the socioeconomic environment, the particularities of the organizational and management structure, the nature of the interpersonal relationships within the team, mediated by the joint work activities and the personal characteristics of the employees in the organization. CONCLUSIONS: Conflicts in hospitals arises due to a variety of factors. The systematic study of the sources of conflicts in the hospital allows to identify the problem areas and to prevent a negative impact on the work of medical staff.
\end{abstract}

Key words: conflict, hospitals, sources of conflict

\section{INTRODUCTION}

The conflict arises at all levels within the hospital as a social organization, and has been identified as a global problem (1-7). It is determined both by internal reasons organizational management, sociopsychological, personal and external (economic, political, socio-cultural), which are interrelated and change over time $(1,5,8,9$, 10). The differentiation and the systematic follow-up of risk factors for conflict development in the hospital help to uncover their form and establish effective strategies for their prevention and resolution (10).

\section{MATERIAL AND METHODS}

By means of direct individual poll was studied the opinion of 302 medical employees at four general hospitals on the teritory of the town of Plovdiv and town of Asenovgrad in the period December 2011- March 2012. We used a set of questions that determine sources of conflicts in hospitals. The data were analysed

\footnotetext{
*Correspondence to: Ekaterina Lyubenova Raykova, Medical University-Plovdiv, Department of Management of health care, Faculty of Public Health, Bulgaria, Plovdiv, blvd. "V. Aprilov" 15a, Telephone number: 0888999 783, e-mail: ekaterina_raikova@abv.bg
}

using descriptive statistics and non-parametric analysis at a significance level for the null hypothesis $\mathrm{p}<0.05$. The statistical analysis was performed using SPSS v. 16.

\section{RESULTS}

In the study are included medical employees divided into categories personnel as follows: managing personnel - $17,92 \pm 2,21 \%$, full-time employees $-82,10 \pm 2,21 \%$. The main part of the interviewed are healthcare specialists (HCS)- $73,8 \pm 2.53 \%$, and $26,2 \pm 2.53 \%$ are physicians. As a whole in the researched contingent dominate women $86.8 \pm 2.0 \%$ verses mans $13.2 \pm 2.0 \%$. The average age of the contingent observed is $44,33 \pm 0,62$ years. The average duration of the work experience is $21,70 \pm 0,65$ years.

In the study of the external factors related to the changes in the health care system causing the emergence of conflicts in the hospital, the medical specialists identified as leading - the improper allocation of the financial revenues from the National Health Insurance Fund /NHIF/ $(56.1 \pm 2.88 \%)$ and the imposed financing model (clinical pathway) (53.7 2.90 $\%)$. At the same time, about one third of the respondents point out the complicated 
documentation from the NHIF $(34.6 \pm 2.77 \%)$ and the servicing of uninsured or partially insured persons $(29.40 \pm 2.65 \%)$.

The opinion of respondents on this issue was studied according to their professional background. Physicians rated as the most conflicting the financing model (clinical pathway) $(69.2 \pm 5.23 \%)$, while the healthcare specialists $(56.4 \pm 3.36 \%)$ - the incorrect
RAYKOVA E., et al. allocation of financial revenues from the NHIF.

The comparison shows a significant difference in the opinion of the physicians and the HCS for three of the external reasons: the financing model (clinical pathway), complicated documentation from the NHIF and the presence of uninsured and partially insured persons (Table 1).

Table 1. External factors leading to the onset of conflicts in hospitals in the opinion of physicians and HCS (in \%)

\begin{tabular}{|c|c|c|c|c|c|c|c|c|c|}
\hline \multirow{2}{*}{ No } & \multirow{2}{*}{$\begin{array}{l}\text { External reasons for } \\
\text { conflicts in hospitals }\end{array}$} & \multicolumn{3}{|c|}{ Physicians } & \multicolumn{3}{|c|}{ HCS } & \multirow[b]{2}{*}{$\mathbf{u}$} & \multirow[b]{2}{*}{$P$} \\
\hline & & Number & $\%$ & $\mathrm{Sp}$ & Number & $\%$ & $\mathrm{Sp}$ & & \\
\hline 1 & $\begin{array}{l}\text { Financing model } \\
\text { (clinical pathway) }\end{array}$ & 54 & 69.2 & 5.23 & 105 & 48.2 & 3.38 & 3.37 & $<0.01$ \\
\hline 2 & $\begin{array}{l}\text { Uninsured and partially } \\
\text { insured persons }\end{array}$ & 32 & 41.0 & 5.57 & 55 & 25.2 & 2.94 & 2.51 & $<0.05$ \\
\hline 3 & $\begin{array}{l}\text { Incorrect allocation of } \\
\text { financial revenues from } \\
\text { the NHIF }\end{array}$ & 43 & 55.1 & 5.63 & 123 & 56.4 & 3.36 & -1.99 & $>0.05$ \\
\hline 4 & $\begin{array}{l}\text { Complicated } \\
\text { documentation from the } \\
\text { NHIF }\end{array}$ & 38 & 49.4 & 5.70 & 64 & 29.4 & 3.08 & 3.09 & $<0.01$ \\
\hline 5 & Organizational change & 4 & 5.2 & - & 24 & 11.0 & 2.12 & - & - \\
\hline
\end{tabular}

*The sum of the percentages of answers exceeds 100 because the respondents indicated more than one answer to the question.

The study found that there is a dependency between the sexes and the opinions of the respondents about the external causes of conflicts. Male respondents refer to the complicated documentation from the NHIF $\mathrm{P}<0.01\left(\chi^{2}=8.53\right)$ and the service of uninsured and partially insured persons - $\mathrm{P}<0.01$ $\left(\chi^{2}=9.47\right)$ as a more common prerequisite for conflict.

Specific conflict factors have been studied in connection with the specific internal environment of the hospital in the following four areas: organizational management, socioeconomic, social and personal factors.

In the study of specific organizational management factors, almost half of the healthcare professionals $(49.5 \pm 2.89 \%)$ report stress as the main cause of conflicts at work. Other more common prerequisites for conflicts are the presence of weaknesses and errors in the management system $(27.5 \pm 2.59 \%)$, the ambiguity of roles and misplaced responsibilities $(20.8 \pm 2.35 \%)$.

In the comparison between the two professional groups it was found that a higher percentage of physicians $(23.4 \pm 4.82 \%)$, compared to the medical healthcare professionals $(10.9 \pm 2.10 \%)$, accept the innovations and the ongoing health care reforms as a precondition for conflicts $\mathrm{P}<0.01\left(\chi^{2}=7.39\right)$.

The results reflecting the socio-economic factors indicate that the majority of the healthcare professionals $(70.2 \pm 2.64 \%)$ define the dissatisfaction with the remuneration as the most significant premise for controversy in the hospitals (Figure 1).

Other significant sources of tension, according to the respondents, are insufficient awareness of the hospital's economic efficiency $(22.5 \pm 2.42 \%)$ and the unjust formation of staff remuneration (21.1 $\pm 2.36 \%)$.

Dependency between the gender and the assessment of the respondents was established in relation to the formation of staff remuneration. Men point to the unjust formation of staff remuneration as a more significant risk factor, initiating conflicts at the workplace $-\mathrm{P}<0.05\left(\chi^{2}=5.32\right)$.

In the study of the conflict factors of individual (personal) nature, the lack of honesty and openness in the working relationship $(33.6 \pm 2.74 \%)$ is the main reason initiating conflicts. The respondents put in the next places the unethical behavior and 
disregard for teamwork (28.9 $\pm 2.63 \%)$ and the inadequately increased self-assessment of some of their colleagues $(20.5 \pm 2.34 \%)$.
RAYKOVA E., et al. The latter is more common among physicians $(31.2 \pm 5.28 \%)$ compared to the medical healthcare professionals $(16.7 \pm 2.51 \%) \quad(\mathrm{P}$ $<0.05, \mathrm{u}=2.48$ ).

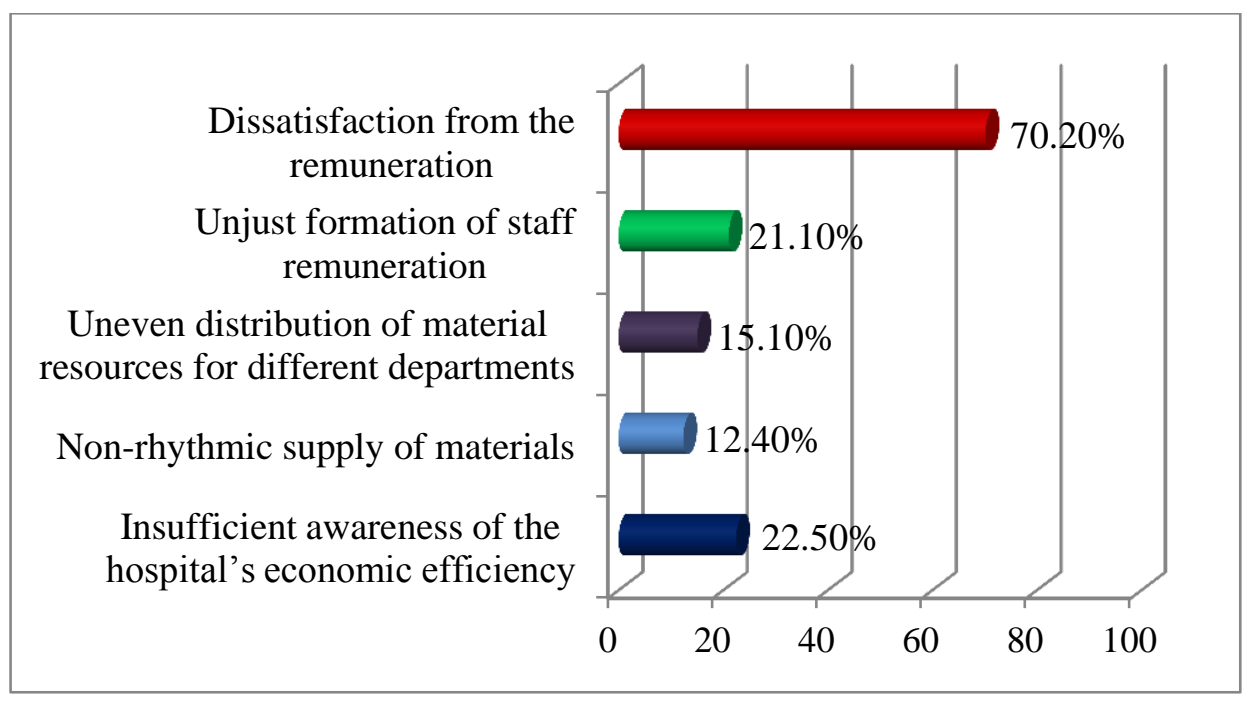

Figure 1. Conflict factors of socio-economic nature

The results reflecting the opinion of medical practitioners on the conflict-related social factors indicate that the unethical behavior in relationships, expressed through inappropriate comments and slander towards colleagues $(48.3 \pm 2.89 \%)$ and patients $(22.8 \pm 2.43 \%)$, are leading causes of conflicts of social nature.

According to $81.1 \pm 2.27 \%$ of the respondents discrimination at work is an essential prerequisite for conflict, and this phenomenon is more common with physicians $(89.9 \pm 3.39 \%)$ than with HCS $(77.9 \pm 2.82 \%)$ - P $<0.01\left(\mathrm{u}=2.72, \chi^{2}=5.43\right)$.

\section{DISCUSSION}

The conflicts in the hospital as a social organization are seen as a special type of interaction based on contradictions in interests, goals and values of people concentrated in formal or informal organizational structure (11). Research has shown that there are a number of internal and external factors that can cause conflicts in hospitals $(1,2,4,5)$. The conflicts in the hospitals are closely related to processes and contradictions brought about by the constant social changes in society. Continued health system reforms, increasing demands and pressure to increase the productivity and the quality of services provided expose hospitals to external influences and are a prerequisite for conflicts (9).

The analysis of the results of a study of external conflict factors shows the existence of hospital conflicts related to the improper allocation of financial revenues from the NHIF $(56.1 \%)$ and the financing model. The NHIF does not have the legal power to require a percentage of the total amount of health insurance payments to be allocated for labor. Therefore, this is a problem of the management of health organizations and is to a certain extent due to the unfair distribution between the different structural units (clinics, wards, laboratories, etc.). The differences in the opinions of physicians and healthcare professionals about external conflict factors reflect their attitudes from a professional point of view (9). The comparison of current data with those from other studies $(9,12,13)$ demonstrates the existence of ongoing and complicated conflicts related to the financing model and the distribution of revenues from the NHIF.

The conflict in hospitals is also determined by the specifics of the internal working environment. The results of the study show that workplace stress is a major cause of conflicts of organizational and managerial nature. This is conditioned by the specific nature of work and the responsibility that the work of the hospital staff is related to. Similar results are also reported by a number of other authors $(5,8,9)$. In the process of conflict, much of the controversy in the workplace is also a consequence of inadequately applied management approaches $(16,17)$. 
Studies show that the conflicting potential of the work environment is conditioned by the nature of the services provided, the day-to-day responsibility and the role of the staff $(1,5$, 17). The lack of clarity regarding the roles and the responsibilities in the implementation of work obligations is a prerequisite for tension and controversy.

Payment for the work of medical personnel is seen as a key factor influencing the potential for tensions and conflicts. A large proportion of the healthcare workers $(70.2 \%)$ defined the dissatisfaction with remuneration as the most significant socio-economic premise for controversy, which is also confirmed by other studies $(12,13,18)$.

The studies that analyze the causes of a conflict during the labor process show that they arise in cases of inconsistency between the actions of medical practitioners and the accepted ethical norms $(19,20,21)$. The lack of honesty and unethicality in the work relationships are major conflict-related factors of a personal nature.

An unhealthy relationship creates distrust among medical people. The lack of trust dissuades the medical staff from performing their professional duties and has a negative impact on the quality of their work $(1,4,19)$.

A potential source of open disagreements among socially-minded medical practitioners is inappropriate comments and slander towards colleagues and patients. Under conditions of competition, such unfair treatment changes the value of hospital positioning in patients' minds and raises the level of dissatisfaction among the public. This is the opinion of other researchers, according to who in the rivalry for a higher public and professional image, the moral values, collegiality and honesty are sacrificed $(9,22)$.

Discrimination in the workplace is a major factor in the emergence of conflicts in the workplace. The results of the study show that a large proportion of healthcare workers $(81.1 \%)$ define workplace discrimination as a risk factor that triggers contradictions. The discrepancies found between the two categories of staff are indicative that physicians are more at risk and are working in hostile or threatening environments.

In a study of the health sector, discrimination is defined as a psychosocial risk with a negative impact on the physical and mental health of the medical staff, which significantly affects the effective operation of the hospital
RAYKOVA E., et al. $(14,23,24)$. The results of the study confirm the thesis of other authors that conflict is the basis of controversies that arise in the course of work, but they only lead to conflict when they affect the social status of a particular group or person, their material or spiritual values, authority (prestige), etc. (25).

\section{RESULTS}

1. The main external factors giving rise to conflicts in hospitals are the incorrect distribution of financial revenues from the NHIF and the financing model (clinical pathway).

2. It is established that the most significant factor for conflicts among physicians is the financing model (clinical pathway) (69.2\%) and among the medical health care professionals - the incorrect allocation of financial revenues from the NHIF (56.4\%).

3. The conflicts in the hospital are determined by the specific nature of the internal working environment, with the leading factors being discrimination in the workplace (81.1\%), inadequate remuneration for work (70.2\%), work stress $(49.5 \%)$, unethical behavior towards colleagues (48.3\%), lack of honesty and openness in the work relationships between medical practitioners (33.6\%).

4. There is a significant difference in the opinions of the groups of specialists surveyed (physicians and healthcare specialists) regarding the leading conflict factors related to the specifics of the hospital's internal working environment.

\section{CONCLUSIONS}

Conflicts in hospitals are caused by different factors, such as the nature, strength and duration of action, which determine its multifaceted manifestation. The systematic study of conflict sources at the hospital allows the identification of problematic areas and the prevention of their negative impact on the work of the medical staff.

\section{REFERENCES}

1. Aberese -Ako, M., Agyepong, I. A., Gerrits, T.,Van Dijk, H. 'I Used to Fight with Them but Now I Have Stopped!: Conflict and Doctor-Nurse-Anaesthetists' Motivation in Maternal and Neonatal Care Provision in a Specialist Referral Hospital. PloS one, 10(8), e0135129, 2015.

2. Akel, D. T., Elazeem, H. A. Nurses and physicians point of view regarding causes of conflict between them and resolution strategies used. Clinical Nursing Studies, 3(4):112, 2015.

3. Archambault-Grenier, M. A., RoyGagnon, M. H., Gauvin, F., Doucet, H., 
Humbert, N., Stojanovic, S., Duval, M. Survey highlights the need for specific interventions to reduce frequent conflicts between healthcare professionals providing paediatric end-of-life care. Acta Paediatrica, 107(2), 262-269, 2018.

4. Pavlakis, A., Kaitelidou, D., Theodorou, M., Galanis, P., Sourtzi, P., Siskou, O. Conflict management in public hospitals: the Cyprus case. International nursing review, 58(2), 242-248, 2011.

5. Polyzou, M., Kilindri S. Conflicts in Hospitals: A quantitative Analysis of Determinant Factors. MIBES Transactions, 129-142, 2017.

6. Stecker, M., Epstein, N., Stecker, M. M. Analysis of inter-provider conflicts among healthcare providers. Surgical neurology international, 4(5), S375, 2013.

7. Yoon, J. D., Rasinski, K. A., \&Curlin, F. A. Conflict and emotional exhaustion in obstetrician-gynaecologists: a national survey. Journal of medical ethics, 36(12), 731-735,2010.

8. Oxenstierna, G., Magnuson Hanson L.L., Widmark, M.,et al. Conflicts at Work The Relationship with Workplace Factors, Work Characteristics and Self-rated. Industrial Health, 2011,49:501-510

9. Cherkezov, T., Thorniova, B., Chaush, S. The hospital environment as a source of conflict in the conditions of change. In: Scientific conference with international participation "Science and society". Scientific researches, IV(I):351-356, 2010.

10. Deccusheva, A. D. Conflict factors and their characteristics. Scientific problems of humanitarian research 3: 217-223, 2010

11. Reshetnikova, K.V. The problem field of organizational conflictology. In: Human Resource Management: Management and Counseling. M: Independent Institute of Civil Society,318, 2004.

12. Stoyanova, R.Turnover of nurses in the South Central Region of Bulgaria Attitudes, Factors and Perspectives. Dissertation, Medical University Plovdiv, 2015 .

13. Atanasov, P. Professional satisfaction of hospital doctors - modern problems and solutions. Dissertation, Trakia UniversityStara Zagora, 2016.

14. Riedmann, A.,Bruck, C,Houtman, I, Vanadzins, I. Second European Survey of Enterprises on New and Emerging Risks (ESENER-2).

EU-OSHA, https://osha.europa.eu, 2016.
15. Georgiev N. Sources of Conflicts in Hospitals. Dissertation,Medical University Sofia, 2016.

16. Levterova B, Dragova E, Dimcheva T, Bakova Desisilava. Conflict management in healthcare organizations Scientific works of the Union of Scientists in Bulgaria-Plovdiv, series G. Medicine, Pharmacy and Dental medicine, XXI(21):24-27, 2017.

17. Todorova M., Mihaylova-Alakidi, V. Aspects of behaviour of Healthcare spetialists in conflict sittuations. Trakia Journal of sciences, 8(2):395-399, 2010.

18. Tarnovska M., Stoyanova, R., Dimova, R. General Practitioner's Ethical Dimentions of Labour Remuneration, Knowledge International Journal, Scientific papers, 23(4):1169-1174, 2018.

19. Michylova V., M. Liochkova, D.Dimitrova, I. Bivolarski. Ethical And Psychological Demensions Of Trust In The Health Care System In the South Of Bulgaria. Asklepios International Annual Of History And Philosophy of The Medicine, IX (XXVIII), 1(66-72), 2014.

20. Chartered Institute of Personnel and Development. Focus on culture change and patient care in the NHS. cipd.co.uk/employeeoutlook, 2013.

21. Erasmus, E., Gilson, L., Govender, V., Nkosi, M. Organisational culture and trust as influences over the implementation of equity-oriented policy in two South African case study hospitals. International journal for equity in health, 16(1):164, 2017.

22. Tarnovska, M. Business Ethical Dimentions of Professional Activities of General Medical Practice, Dissertation for conferring the Degree "Doctor of Philosophy", Medical University Plovdiv, 2014.

23. Milczarek, M. Workplace violence and harassment: a European picture. Publications Office of the European Union, 2010: 28-40 . doi:10.2802/12198

24. Occupational health and safety risks in the healthcare sector. European Union, , ISBN 978-92-79-19454-2, doi:10.2767/27263, https://publications.europa.eu, 2011.

25. Cherepkova, N.V., Chugunkin, S.A. Sociopsychological climate as an integral part of the work process in the team. General and Clinical Psychology. Bulletin of Medical Internet Conferences, 1(1):45-48, 2011. 